\title{
Expression of CXCL12 receptors in B cells from Mexican Mestizos patients with systemic lupus erythematosus
}

\author{
Vincent Biajoux ${ }^{1,2 \dagger}$, Alexandre Bignon ${ }^{1,2 \dagger}$, Christelle Freitas ${ }^{1,2}$, Valérie Martinez ${ }^{1,2,3}$, Marcus Thelen ${ }^{4}$, \\ Guadalupe Lima ${ }^{5}$, Juan Jakez-Ocampo ${ }^{5}$, Dominique Emilie ${ }^{1,2,6^{\wedge}}$, Luis Llorente ${ }^{5}$ and Karl Balabanian ${ }^{1,2^{*}}$
}

\begin{abstract}
Background: Systemic Lupus Erythematosus (SLE) is a chronic autoimmune disease characterized by B-cell hyperreactivity and the production of pathogenic anti-nuclear-directed auto-antibodies (Abs). B-cell ontogeny is partly dependent on the CXCL12/CXCR4 axis for which the contribution to SLE pathogenesis remains unclear. CXCR7, the novel receptor for CXCL12, is differentially expressed among memory B-cell subsets. However, its biological role in SLE remains to be explored.
\end{abstract}

Methods: Relative CXCR4 and CXCR7 expression levels were compared by quantitative PCR in leukocytes from blood samples of 41 Mexican Mestizos patients with SLE and 45 ethnicity-matched healthy subjects. Intracellular and membrane expression of both receptors was analyzed by flow cytometry in naive and Ab-secreting B cells. B-cell responsiveness to CXCL12 was investigated using Transwell-based chemotaxis assays. Data were analyzed using the Kruskal-Wallis test for comparisons of values amongst healthy controls and patients with inactive or active SLE, and non-parametrically using the Mann-Whitney U-test for multiple comparisons and unpaired samples. Correlations were determined by Spearman's ranking.

Result: SLE leukocytes displayed reduced levels of CXCR4 and CXCR7 transcripts. In SLE patients, a significant defect in CXCR4 expression was detected at the surface of naive and Ab-secreting B cells, associated with an abnormal intracellular localization of the receptor. CXCR7 predominantly localized in cytosolic compartments of B cells from healthy and SLE individuals. Disease activity did not impact on these expression patterns. Altered receptor compartmentalization correlated with an impaired CXCL12-promoted migration of SLE B cells.

Conclusions: Our data highlight a down-regulation of CXCL12 receptors on circulating B cells from SLE patients that likely influences their migratory behavior and distribution.

Keywords: Autoimmunity, Systemic Lupus Erythematosus, B cells, Chemokines, CXCR4, CXCR7, Migration

\section{Background}

Systemic Lupus Erythematosus (SLE) is a prototypical chronic and systemic autoimmune disease with heterogeneous clinical manifestations and various immune dysfunctions [1]. Genetic factors play an important role in

\footnotetext{
*Correspondence: karl.balabanian@u-psud.fr

${ }^{\dagger}$ Equal contributors

Deceased

"Université Paris-Sud, Laboratoire "Cytokines, Chimiokines et Immunopathologie", UMR_S996, Clamart, France

${ }^{2}$ INSERM, Laboratory of Excellence in Research on Medication and Innovative Therapeutics (LERMIT), Clamart, France

Full list of author information is available at the end of the article
}

the susceptibility to SLE development [2]. Such complex disease affects multiple organs and results in death particularly when kidney damage is severe. SLE is notably characterized by a strong humoral response. A wide array of intrinsic B-cell defects, including B-cell hyper-reactivity and the production of auto-antibodies (Abs) against dsDNA and ribonucleoproteins, has been documented in SLE patients $[3,4]$. These pathogenic anti-nuclear Abs are thought to agglomerate and form immune complexes, thus leading to organ destruction [5]. Perturbations of peripheral B-cell homeostasis (e.g. increased CD27 ${ }^{\text {high }}$ plasma cells $[\mathrm{PC}]$ ), deposition of immune complexes and

\section{() Biomed Central}


complement activation further underscore the contribution of B cells to SLE pathogenesis [6-8]. Hence, B-cell targeted therapies such as rituximab and epratuzumab, two humanized monoclonal Abs (mAbs) directed against surface molecules CD20 and CD22 respectively, are of interest for improving current treatments mostly based on non-specific immunosuppressive drugs $[7,9]$.

Chemokines are small cytokine-like secreted proteins that govern migration of leukocytes to specific niches in lymphoid organs and inflammatory sites. They mediate their functions by binding and activating chemokine receptors, which belong to the seven-transmembrane $\mathrm{G}$ proteincoupled receptor family [10]. The chemokine system influences the inflammatory development and progression of B-cell mediated autoimmune diseases including SLE $[3,11,12]$. In this study, we focused on the CXC $\alpha$-chemokine Stromal cell Derived Factor-1 (SDF-1)/CXCL12, which together with its main receptor CXCR4, constitutes the chemokine/receptor axis attracting the greatest level of interest in autoimmunity [13]. Many leukocytes, including B cells, express CXCR4 and CXCL12 is constitutively produced by stromal, epithelial, and endothelial cells notably in lymphoid organs [14,15]. Given its ability to regulate Bcell ontogeny, differentiation and homing, recent attention has been directed to the CXCL12/CXCR4 axis in SLE pathophysiology. CXCL12 is upregulated in the tubules and glomeruli of nephritic kidneys from multiple lupusprone mouse models (e.g. NZB/W, BXSB, MRL.lpr) and SLE patients as well $[13,16,17]$. Similarly, CXCR4 hyperexpression or -activity has been reported in various leukocyte subsets of lupus mouse models [13]. Thus, in concert with CXCL12, CXCR4 could be pivotal for leukocyte trafficking into damaged kidneys from mice with lupus nephritis. In SLE patients, the situation is somewhat puzzling, as contradictory results have been reported for CXCR4 expression on peripheral blood lymphocytes. Indeed, some studies have documented down- or upregulation of CXCR4 expression on SLE B cells, while others failed to detect any change in membrane CXCR4 expression $[8,13,16,18]$. To our knowledge, there is currently no consensus on CXCR4 expression and its correlation with SLE.

Little if anything is known about the expression and role of CXCR7, the second receptor for CXCL12, in SLE pathogenesis. CXCR7 binds with high affinity to CXCL12 and with lower affinity to Interferon-inducible T-cell Alpha Chemoattractant (I-TAC)/CXCL11, but its signaling capacities are still subject of debate [19,20]. Unlike CXCR4, CXCR7 does not signal through the canonical Goi-protein pathways and thus, is unable to activate conventional signaling events [20]. However, CXCR7 could act as a decoy receptor that is able to clear CXCL12 from the surrounding medium [21-24]. CXCR7 is expressed on multiple cell types including endothelial and tumor cells and was shown to promote cell survival, adhesion and tumor growth, suggesting a signaling potential for this atypical receptor [19]. This may rely on its reported ability to behave as an endogenous $\beta$ arrestin-biased receptor or to complex with CXCR4, forming heterodimers that regulate CXCL12 responsiveness [25-28]. The expression profile of CXCR7 in mouse and human hematopoietic cells was recently disputed [19,29-31]. It appears to be expressed on B cells, tightly regulated during B-cell differentiation and correlated with the capacity of memory $B$ cells to differentiate into $\mathrm{Ab}$-secreting cells, i.e. $\mathrm{PC}$, which are increased in the blood of patient with active SLE [6-8,21,30,32,33]. Whether CXCR7 dysregulation characterizes SLE remains to be delineated.

The aim of this study was to examine the expression of CXCR4 and CXCR7, together with CXCL12 responsiveness, in circulating B-cell subsets from Mexican Mestizos SLE patients and age- and ethnicity-matched healthy subjects. Our data reveal that both CXCR4 and CXCR7 are downregulated on SLE B cells.

\section{Methods}

\section{Ethics statement}

The study was carried out in accordance with good clinical practice guidelines, national laws and the Declaration of Helsinki, and was approved by the Institutional Committee of Biomedical Research (Comité Institucional de Investigación Biomédica en Humanos). All patients signed an informed consent.

\section{Patients, sample processing and cell culture}

The study included 41 SLE patients (37 women and 4 men) with median age of 36 years (range: 21 to 62 ) and median disease duration of 8 years (range: 1 to 27) (Table 1). All patients were Mexican Mestizos [34], recruited in the Department of Immunology and Rheumatology of the Hospital "Instituto Nacional de Ciencias Mèdicas y Nutriciòn Salvador Zubiràn" (Mexico City, Mexico) and fulfilled at least four 1982 American Rheumatism Association revised criteria for SLE [35]. Clinical disease activity was scored using the SLE Disease Activity Index or SLEDAI [36]. 17 patients had inactive disease (SLEDAI $\leq 3)$ and 24 patients with indices above 3 were considered as having active disease as recently reported [37]. The five patients who had neuropsychiatric (NP) or central nervous system (CNS) history were inactive regarding these manifestations at the time of the study. All patients with renal involvement and SLEDAI > 4 had active disease at the time of the study, meaning that most of active patients displayed active renal involvement $(n=20)$. Donors of control leukocytes consisted in age- (median 41.4 years, range: 23 to 60 years) and sexbiased (male/female ratio $=0.6) 45$ healthy adult volunteers, 
Table 1 Demographic, pathophysiological and treatment characterization of SLE patients

\begin{tabular}{|c|c|c|c|}
\hline Parameters & Inactive SLE (SLEDAI $\leq 3$ ) & Active SLE (SLEDAI > 3) & $P$ value $^{a}$ \\
\hline Total numbers $(\mathrm{n})$ & 17 & 24 & $N / A^{b}$ \\
\hline \multicolumn{4}{|l|}{ Age at study (years) } \\
\hline Median & 35 & 36 & 0.474 \\
\hline Range & $21-62$ & $25-50$ & \\
\hline \multicolumn{4}{|l|}{ Sex (n) } \\
\hline Female & 15 & 22 & N/A \\
\hline Male & 2 & 2 & N/A \\
\hline \multicolumn{4}{|l|}{ Duration of disease (years) } \\
\hline Median & 8 & 8 & 0.577 \\
\hline Range & $1-22$ & $1-27$ & \\
\hline \multicolumn{4}{|c|}{ Clinical parameters (mean \pm SD) } \\
\hline White Blood Cells $\left(\times 10^{9} / \mathrm{L}\right)$ & $5.6 \pm 1.8$ & $4.9 \pm 1.8$ & 0.218 \\
\hline \multicolumn{4}{|l|}{ Clinical signs ( $\mathrm{n}$ ) } \\
\hline Muco-cutaneous & 11 & 13 & N/A \\
\hline Haematological & 8 & 12 & N/A \\
\hline Neurological/Psychiatric & - & 5 & N/A \\
\hline Serositis & - & 6 & N/A \\
\hline Renal & 6 & 20 & N/A \\
\hline Joint & 12 & 14 & N/A \\
\hline \multicolumn{4}{|c|}{ SLE activity (mean \pm SD [range]) } \\
\hline SLEDAI score & $0.4 \pm 0.2[0-2]$ & $9.1 \pm 3.8[4-18]^{* * *}$ & $<0.0001$ \\
\hline \multicolumn{4}{|c|}{ B-cell subsets (mean \pm SEM [range], $\times 10^{6} / L$ ) } \\
\hline Total CD19+ B cells & $554.2 \pm 121.9[54-2077]$ & $319.3 \pm 73.9[6-1303]$ & 0.0585 \\
\hline CD27 naive $B$ cells & $398.6 \pm 104.1[17.9-1757]$ & $217.1 \pm 62.1[0.7-1205]^{*}$ & 0.0403 \\
\hline Overall CD27 ${ }^{+}$B cells & $146.2 \pm 22.7[35.1-323.2]$ & $96.6 \pm 16.8[5.3-292.8]$ & 0.0585 \\
\hline $\mathrm{CD} 27^{+}$memory B cells & $127.5 \pm 20.1[30.3-273.6]$ & $82.8 \pm 15.2[1.9-279.3]$ & 0.0534 \\
\hline CD27 ${ }^{\text {high }}$ plasma B cells & $19 \pm 3.3[4.9-49.6]$ & $13.9 \pm 2.6[0.9-44.2]$ & 0.0879 \\
\hline \multicolumn{4}{|l|}{ Treatment (n) } \\
\hline None & 4 & 1 & N/A \\
\hline Prednisolone & 5 & 20 & N/A \\
\hline Azathioprine & 8 & 19 & N/A \\
\hline Methotrexate & 2 & 1 & N/A \\
\hline Hydroxychloroquine & 6 & 7 & N/A \\
\hline Mycophenolate Mofetil & 2 & 3 & N/A \\
\hline Cyclophosphamide & - & 2 & N/A \\
\hline Leflunomide & - & 1 & $\mathrm{~N} / \mathrm{A}$ \\
\hline
\end{tabular}

${ }^{a}$ Mann-Whitney $U$-test; ${ }^{b} \mathrm{~N} / \mathrm{A}$ : Not Applicable.

among which 13 were referred at the Établissement Français du Sang (Rungis, France) and 32 at the Hospital "Instituto Nacional de Ciencias Mèdicas y Nutriciòn Salvador Zubiràn". Healthy subjects were seronegative for human immunodeficiency virus, hepatitis $\mathrm{B}$ or $\mathrm{C}$ virus, without evidence of cancer, congenital heart disease or connective tissue disorder. No differences were detected in CXCL12 receptors expression and function in circulating lymphocytes from both French and Mexican healthy controls.

Within 2 hours after blood sampling either in Mexico or France, peripheral blood mononuclear cells (PBMC) were isolated in a similar fashion from heparin-treated blood samples using Ficoll-Paque Plus (Amersham Biosciences AB, Uppsala, Sweden) density gradient centrifugation and 
then cryopreserved in $1 \mathrm{~mL}$ fetal calf serum (FCS) with $10 \%$ dimethylsulfoxide. After transportation in France, SLE and healthy PBMC were defrozen by rapid thawing at $37^{\circ} \mathrm{C}$ in parallel with French samples and immediately transferred to $10 \mathrm{~mL}$ FCS. Leukocytes were $>90 \%$ viable upon thawing, as assessed by trypan-blue exclusion. After washing twice with $10 \mathrm{~mL}$ PBS $1 \mathrm{X}, \mathrm{PBMC}$ were incubated $60 \mathrm{~min}$ at $37^{\circ} \mathrm{C}$ in RPMI medium supplemented with $20 \mathrm{mM}$ HEPES and $0.5 \%$ bovine serum albumin (BSA), a step allowing resensitization of chemokine receptors including CXCR4 [38]. As specified in some experiments, whole blood and PBMC were used right after collection. Parental, CXCR4- and CXCR7-transduced HEK 293 T (HEK) cells [29] were maintained in Dulbecco's modified Eagle's medium supplemented with $10 \%$ FCS, glucose (4.5 g/L), $10 \mathrm{mM}$ HEPES, penicillin (100 units $/ \mathrm{mL})$ and streptomycin $(100 \mu \mathrm{g} / \mathrm{mL})$ at $37^{\circ} \mathrm{C}$ in humidified air with $5 \% \mathrm{CO}_{2}$.

\section{Real-time RT-PCR analysis}

Total cellular RNA was extracted from PBMC samples using the RNeasy Plus Mini kit and genomic DNA (gDNA) Eliminator columns (Qiagen, Courtaboeuf, France) and reverse transcribed with $\mathrm{pd}(\mathrm{T})-15$ and Moloney Murine Leukemia Virus reverse transcriptase (Fisher Bioblock, Illkirch, France). RNA quality and integrity were assessed by detecting both $18 S$ and $28 S$ ribosomal RNAs in each sample and using a BioAnalyzer (Agilent), respectively. As determined using the NanoDrop technology, all samples displayed a RNA A260/280 ratio $~ 2.0$ and a RNA Integrity Number $>7$ and were then processed for gene expression. Amplification of cDNAs $(1 \mu \mathrm{g})$ was performed by quantitative real-time PCR reactions on a Light Cycler instrument (LC480, Roche Diagnostics, Meylan, France) with the LightCycler 480 SYBR Green detection kit (Roche Diagnostics) using forward (450-467) 5'-GACCGCTACCTGGCCATC-3' and reverse (743-761) 5'-GGCAGCCAACAGGCGAAGA-3' primers for CXCR4 (311 bp), forward (8-29) 5'-TGCA TCTCTTCGACTACTCAGA-3' and reverse (94-113) 5'GGCATGTTGGGACACATCAC-3' primers for CXCR7 (103 bp), and forward (214-223) 5'-GGGTCAGAAGGA TTCCTATG-3' and reverse (432-451) 5'-GGTCTCAAAC ATGATCTGGG-3' primers for $\beta$-actin (237 bp). We used the LightCycler 480 Real-Time PCR system (Roche Diagnostics) with the following amplification scheme: $95^{\circ} \mathrm{C}$ $10 \mathrm{~min}$ and 40 cycles: $95^{\circ} \mathrm{C} 20 \mathrm{~s}, 60^{\circ} \mathrm{C} 15 \mathrm{~s}, 72^{\circ} \mathrm{C} 20 \mathrm{~s}$. The dissociation curve method was applied according to manufacturer's protocol $\left(60^{\circ} \mathrm{C}\right.$ to $\left.95^{\circ} \mathrm{C}\right)$ to ensure the presence of a single specific PCR product. Relative quantification was performed with the standard curve method as we previously used [33,39]. For each tested gene (i.e. CXCR4, CXCR7 or $\beta$-actin), standard cDNAs from PHA-stimulated PBMC were amplified along with sample cDNAs in the same PCR run. Standard curves were generated by the LC480 software (Roche Diagnostics). The threshold fluorescence common for all compared samples was set into the exponential phase of the amplifications. The target mRNA quantity in each sample was determined from the relative standard curve (using sample Ct values) and expressed in arbitrary units (AU) corresponding to the dilution factors of the standard RNA preparation. Amplification efficiency representative for each gene was determined using equation of the standard curve as reported elsewhere [40]. Results

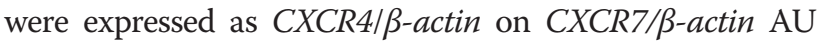
ratios. Internal positive controls, consisting in CXCR4- or CXCR7-transduced HEK cells, were run in parallel. We controlled that no gDNA was amplified in all cDNA samples tested using the following intron-spanning primers: forward (939-958) 5'-CACTCCCGCCCAATATACCC-3' and reverse (1218-1237) 5'-ACACACAAAGAGGCCAC TCC-3' primers for CXCR4 (298 bp) and forward (353372) 5'-CTACAGCCACAGAAAGCGGA-3' and reverse (527-546) 5'-GGAAAGGAAAACTGCCAGCG-3' primers for CXCR7 (193 bp).

\section{Flow-cytometric analysis}

The frequency of each B-cell subset and membrane expression levels of both CXCR4 and CXCR7 were determined by four-color flow-cytometric analysis. For this purpose, PBMC were incubated with the following mAbs (unless specified from BD Pharmingen, Le Pont de Claix, France): fluorescein isothiocyanate (FITC)-conjugated mouse anti-human CD27 (clone M-T271), unconjugated mouse anti-human CXCR7 (clone 9C4) followed by a phycoerythrin (PE)-conjugated goat anti-mouse $\mathrm{F}\left(\mathrm{ab}^{\prime}\right)_{2}$ Ab (Dako, Trappes, France) as previously described [29], PE-conjugated mouse anti-human CD38 (clone HIT2) or CXCR7 (clone 11G8, R\&D Systems, Lille, France or clone 8F11-M16, BioLegend, San Diego, CA), peridinin chlorophyll protein-Cy5 (PerCP-Cy5)-conjugated mouse anti-human CD19 (clone HIB19), and allophycocyanin (APC)-conjugated mouse anti-human CXCR4 (clone 12G5) or CD20 (clone 2H7). Isotype- and speciesmatched Abs were used as negative controls. After wash in PBS 1X, cells were analyzed on a FACSCalibur cytometer (BD Biosciences) using the CellQuest software (BD Biosciences). At least 30,000 events were collected for each analysis after gating on forward and side scatter to select living lymphocytes. The frequencies of naive $\left(\mathrm{CD} 19^{+} \mathrm{CD} 27^{-}\right)$, memory $\left(\mathrm{CD} 19^{+} \mathrm{CD} 27^{+}\right)$and plasma $\left(\mathrm{CD} 19^{\text {low }} \mathrm{CD} 27^{\text {high }}\right) \mathrm{B}$ cells were calculated according to statistical threshold sets in reference of control staining (Figure 1A and Table 1), as previously reported [6]. CXCR4- or CXCR7-transduced HEK cells were used as positive controls for specific staining. To assess total pool of CXCR4 and CXCR7, i.e. membrane and intracellular detection, PBMC were incubated with FITC- 


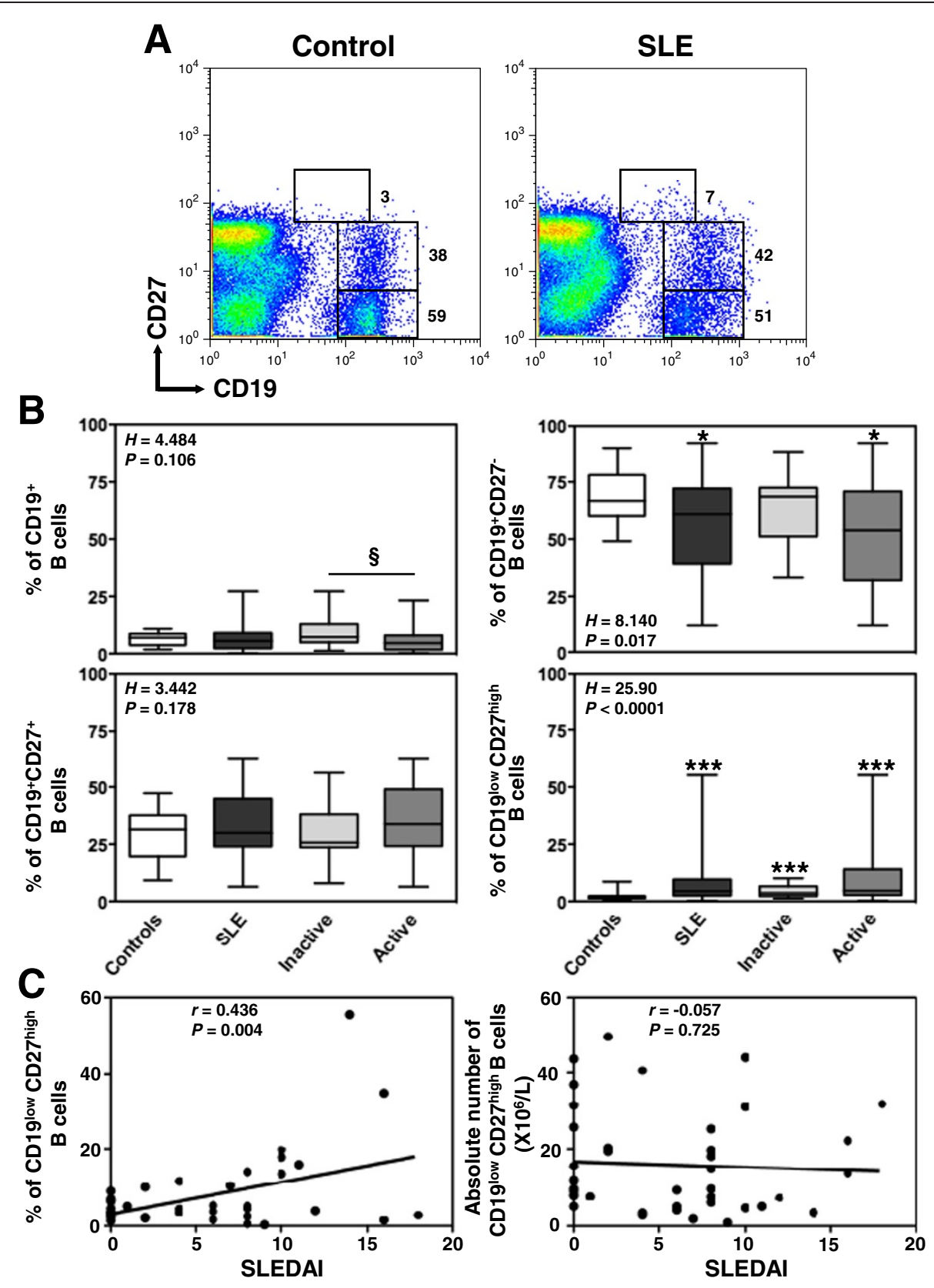

Figure 1 Increased frequency of circulating plasma cells in SLE patients. (A) Double staining with CD19 and CD27 was performed on PBMC to delineate naive $\left(C D 19^{+} C D 27\right) B$ cells, memory $\left(C D 19^{+} C D 27^{+}\right)$B cells and plasma (PC, CD19 $\left.19^{\text {low }} C D 27^{\text {high }}\right)$ cells. Thresholds and fluorescence gates used for the statistical evaluation of $\mathrm{CD} 27^{7}, \mathrm{CD} 27^{+}$and $\mathrm{CD} 27^{\text {high }} \mathrm{B}$ lymphocytes are indicated as well as the corresponding frequency of these subsets among total B cells. Expression of CD27 on CD19+ peripheral B cells is shown for a representative healthy blood donor and a patient with active SLE. (B) Comparison of the frequencies of total B cells among PBMC and of the different B-cell subpopulations from SLE patients $(n=41)$, distributed according to disease activity, i.e. inactive $(n=17)$ versus active $(n=24)$, and from healthy individuals $(n=45)$. The proportions were determined by flow-cytometric analysis as shown in $\mathbf{A}$. Results are depicted as box plots, with median (horizontal line within each box) and $10^{\text {th }}, 25^{\text {th }}, 75^{\text {th }}$, and $90^{\text {th }}$ percentiles (bottom bar, bottom of box, top of box, and top bar, respectively). Kruskal-Wallis $H$ test and associated $P$ values are indicated. ${ }^{*} P<.05$ and ${ }^{* * *} P<.0005$ compared with control B cells. ${ }^{\S} P<.05$ compared with B cells from patients with inactive SLE (as determined using the Mann-Whitney U-test). (C) Frequency (left panel) or total number (right panel) values obtained within CD27 high PC for each SLE patient were plotted as a function of SLEDAl scores. Correlation factor ( $r$, Spearman's) and $P$ value are indicated. 
conjugated mouse anti-human CD27 and PerCP-Cy5conjugated mouse anti-human CD19 mAbs, washed twice in PBS 1X, fixed and permeabilized using the BD Cytofix/ Cytoperm Fixation/Permeabilization Kit (BD Biosciences) according to the manufacturer's instructions. Cells were subsequently stained with 9C4 and 12G5 mAbs, or the corresponding isotype $\mathrm{Ab}$, at room temperature for $30 \mathrm{~min}$ and then analyzed by flow cytometry.

\section{Chemotaxis assays}

Chemotaxis was performed using a Transwell assay upon CXCL12 or EBI1-Ligand Chemokine (ELC)/CCL19 induction as previously described [29]. Briefly, $3 \times 10^{5} \mathrm{PBMC}$ in $150 \mu \mathrm{L}$ RPMI medium supplemented with 20 mM HEPES and $0.5 \%$ BSA were added to the upper chamber of a 6.5$\mathrm{mm}$ diameter, $5-\mu \mathrm{m}$ pore polycarbonate Transwell culture insert (Corning costar, Brumath, France). The same media $(600 \mu \mathrm{L})$ with or without CXCL12 (chemically synthesized by Dr. F. Baleux, Unité de Chimie Organique, Institut Pasteur, Paris, France) or CCL19 (R\&D Systems) diluted at various concentrations was placed in the lower chamber. AMD3100 (Sigma-Aldrich, Saint-Quentin Fallavier, France) was used at $1 \mu \mathrm{M}$ to inhibit CXCR4-dependent signaling. Input leukocytes that migrated to the lower chamber after 2-hour incubation at $37^{\circ} \mathrm{C}$ in humidified air with $5 \% \mathrm{CO}_{2}$ were collected, stained with CD19, CD20, CD38 and CD27 mAbs, and counted by flow cytometry. The fraction of cells migrating across the polycarbonate membrane was calculated as follows: [(number of cells migrating to the lower chamber in response to chemokine or medium)/(number of cells added to the upper chamber at the start of the assay) $] \times 100$.

\section{Statistical analysis}

Unless specified, all values are expressed as median $\left(25^{\text {th }}\right.$ and $75^{\text {th }}$ percentiles). Data were analyzed using the KruskalWallis test for comparisons of values amongst at least three groups, i.e. healthy controls, patients with inactive or active SLE, when required, and non-parametrically using the Mann-Whitney $U$-test (Prism software, GraphPad, La Jolla, CA) for multiple comparisons and unpaired samples. Correlations were determined by Spearman's ranking. $P$ values lower than 0.05 were considered statistically significant.

\section{Results}

\section{Altered B-cell distribution in the peripheral blood of SLE patients}

Cryopreserved PBMC of all 41 Mexican Mestizos patients with SLE and 45 age- and ethnicity-matched independent healthy subjects were analyzed by flow cytometry to determine the frequencies of naive, memory and plasma B cells. Consistent with previous works $[1,41]$, several abnormalities of the B-cell compartment were detected in the peripheral blood of SLE patients including a B-cell lymphopenia that predominantly affects naive $\mathrm{B}$ cells (Figure $1 \mathrm{~B}$ and Table 1). In contrast, a significant increase in the frequency of PC was observed in patients with SLE (Figure 1A). Comparison of the proportions of the different B-cell subpopulations from SLE patients distributed according to disease activity, i.e. inactive $(\mathrm{n}=17$, SLEDAI $\leq 3)$ versus active $(\mathrm{n}=$ 24, SLEDAI > 3), revealed more marked B-cell alterations in the blood of patients with active SLE. No significant correlation could be detected between white blood cell count and disease activity, duration or organ alteration (i.e. renal, muco-cutaneous). In accordance with previous reports [6,32], only the frequency of PC positively and significantly correlated with the disease activity among peripheral B-cell subsets (Figure 1C). Taken together, our data confirmed perturbations of peripheral B-cell homeostasis, which were more pronounced in patients with active disease. The implication of CXCR4 and CXCR7 in the terminal differentiation of B cells into Ab-secreting cells $[15,30]$ prompted us to investigate whether altered B-cell distribution in SLE was associated with changes in CXCL12 receptors expression.

\section{Reduced levels of CXCR4 and CXCR7 mRNAs in SLE leukocytes}

We have set up real-time PCR analysis to quantify relative levels of CXCR4 and CXCR7 mRNAs in SLE PBMC as compared with those detected in the 45 healthy individuals. Transcripts encoding CXCR4 were readily detectable in leukocytes from healthy subjects (Figure 2A). Likewise, CXCR7 mRNAs could be amplified in control leukocytes (Figure 2B). Expression levels of both CXCR4 and CXCR7 mRNAs scattered over a large range among donors, likely as the consequence of an inter-individual variability $[33,42,43]$. However, the levels of CXCR4 and CXCR7 transcripts were significantly decreased in leukocytes from patients with active disease as compared to control cells (Figures 2A and B). Amounts of CXCR4 and CXCR7 mRNAs seemed to negatively correlate with SLEDAI scores, although this did not reach statistical significance (Figures $2 \mathrm{C}$ and D). Disease duration and muco-cutaneous manifestation did not impact on CXCR4 or CXCR7 expression. When comparing the group with renal failure history $(n=26)$ with that of non-renal-affected patients $(\mathrm{n}=15)$, we did not find any significant differences between both groups regarding CXCR4 or CXCR7 expression. Thus, our results unveiled a decrease in $C X C R 4$ and CXCR7 mRNA content in PBMC from SLE patients, which is more pronounced in those with active disease.

\section{Defective membrane expression of CXCR4 and CXCR7 in SLE B lymphocytes}

We next assessed whether such transcriptional anomaly could result in reduced protein levels on circulating B cells. A global flow-cytometric analysis of the expression of 

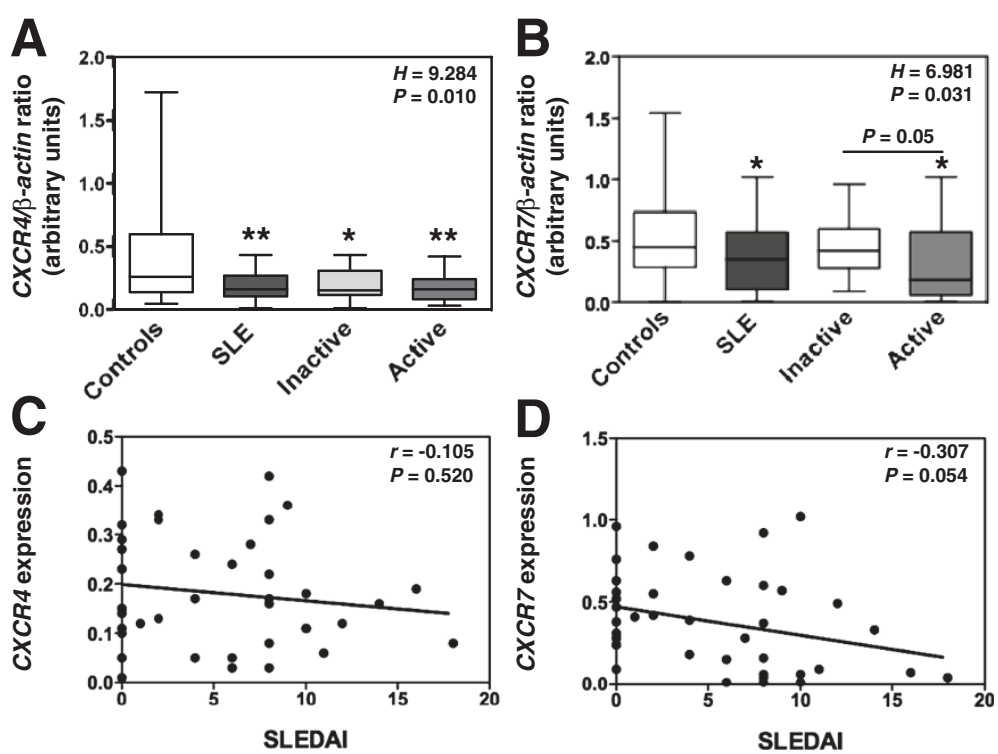

Figure 2 Decreased levels of $C X C R 4$ and CXCR7 mRNAs in active SLE leukocytes. (A and B) The relative levels of CXCR4 (A) and CXCR7 (B) transcripts in PBMC from SLE patients, distributed according to disease activity (i.e. inactive versus active), were compared by real-time PCR with those from healthy individuals. Each individual sample has been run in triplicate. Results are expressed as CXCR4/ $\beta$-actin or CXCR7/ $\beta$-actin AU ratio and presented as box plots with median values, $25^{\text {th }}$ and $75^{\text {th }}$ quartile and the range of values. Kruskal-Wallis $H$ test and associated $P$ values are indicated. ${ }^{*} P<.05$ and ${ }^{* *} P<.005$ compared with control leukocytes (as determined using the Mann-Whitney U-test). (C and D) Correlation scatter plots of CXCR4 (C) or CXCR7 (D) mRNA levels and SLEDAl scores. Correlation factor ( $r$, Spearman's) and $P$ value are indicated.

CXCR4 and CXCR7 was performed on the three B-cell subpopulations, i.e. naive B cells, memory B cells and PC, in the control and SLE groups. As shown in Figure 3A, most peripheral blood $\mathrm{B}$ cells of healthy donors expressed CXCR4 (median value $82 \%$, range: 41 to $99 \%$ ). The percentage of CXCR4-positive cells decreases as control $\mathrm{B}$ cells differentiate to PC (Figure 3B). In addition, CXCR4 surface expression reached different levels on total B cells (geometric mean fluorescence intensity (MFI) median value 55, range: 11 to 217 ) and the different B-cell subsets as well (Additional file 1: Figure $\mathrm{S} 1 \mathrm{~A})$. In line with previous works [41], CXCR4 expression on circulating B cells was significantly lower in SLE patients than in healthy controls (Figures 3A and $\mathrm{B}$ and Additional file 1: Figure S1A). Because the decrease in CXCR4 expression could be due to changes in the proportion of B-cell subsets or variations in expression levels within subsets, we performed an intra-subset analysis. Both frequencies of CXCR4-positive $\mathrm{B}$ cells and expression levels of CXCR4 within naive, memory and PC subsets were markedly reduced in patients with SLE (Figure 3B and Additional file 1: Figure S1A). Strikingly, B cells from patients with either inactive or active disease displayed a comparable defect in cell surface CXCR4 expression in the three subsets analyzed. Therefore, and similarly to the disease duration or organ manifestation (i.e. renal, muco-cutaneous), the disease activity did not impact on the level of CXCR4 expression. Consequently, no significant correlation could be detected between SLEDAI scores and CXCR4 expression on total B cells (Figures 3C and D).

We concomitantly assessed $C X C R 7$ protein expression on B-cell subpopulations using the $9 \mathrm{C} 4 \mathrm{mAb}$, which has been previously reported to specifically react with human CXCR7 [29,30,33]. Confirming this, the 9C4 mAb stained CXCR7-transduced, but not parental, HEK cells (Figure 4A). Compared with CXCR4, we observed only low levels of CXCR7 (median value 4.8\%, range: 0.2

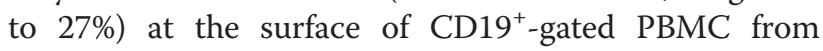
healthy individuals (Figure 4B). CXCR7 remained scarcely expressed on maturating, including memory, B cells. Similar staining patterns were obtained using commercially available 11 G8 and 8F11-M16 anti-CXCR7 mAbs. CXCR7 expression on naive and overall $\mathrm{CD} 27^{+} \mathrm{B}$ cells was still significantly lower in SLE patients than in healthy controls. However, as for CXCR4, there was no correlation between CXCR7 expression levels and the clinical activity of SLE (Figure 4C).

When we compared patients with $(n=25)$ or without $(\mathrm{n}=16)$ prednisolone-based treatment, no significant differences were found between both groups in term of receptors levels. As most active patients received 30 or $50 \mathrm{mg} /$ day prednisolone, we thus cannot assigned an impact of steroids on CXCR4 or CXCR7 expression. Taken together, these findings unraveled a down-regulation of CXCL12 receptors on circulating B-cell subsets from SLE patients. We next addressed whether this loss of 


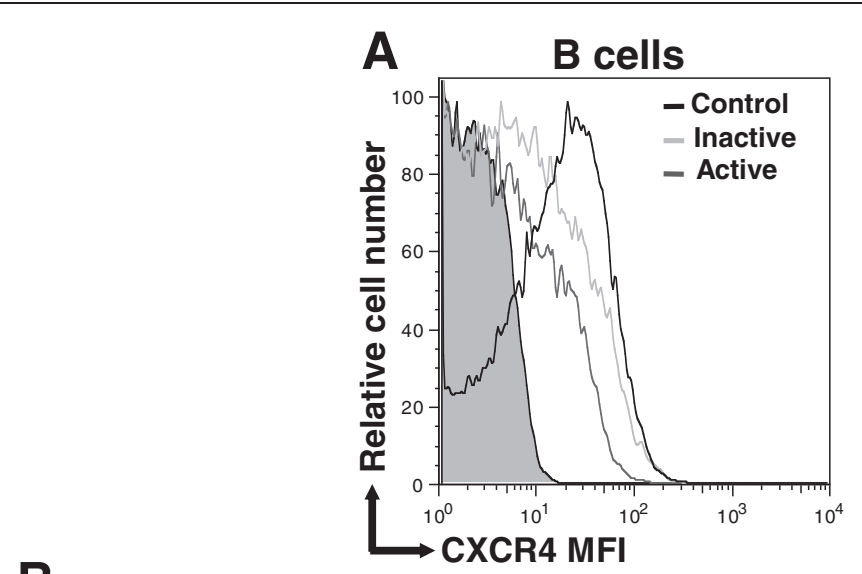

B
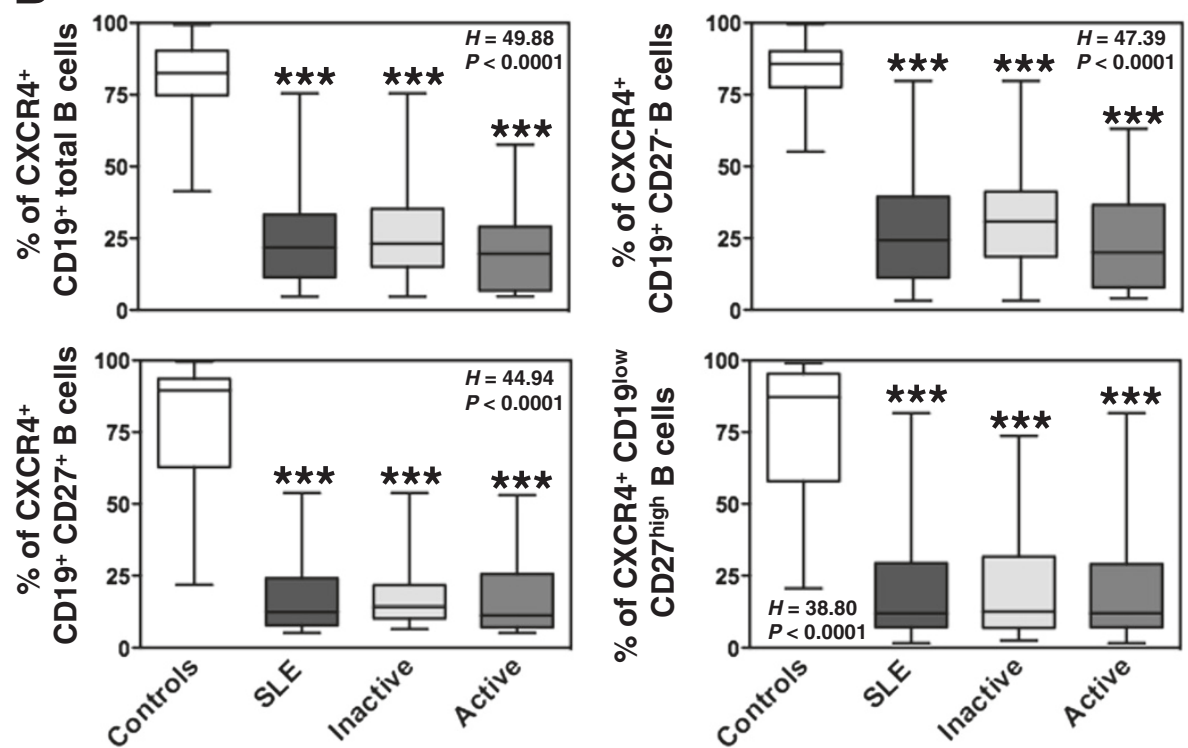

C

D
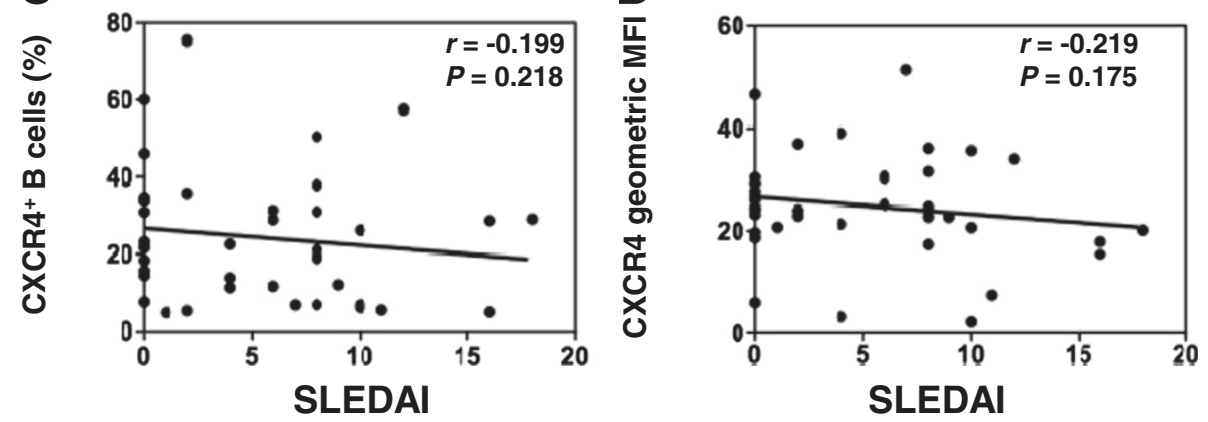

Figure 3 Loss of CXCR4 expression on SLE B cells. (A) Membrane expression of CXCR4 on CD19 ${ }^{+}$-gated PBMC from healthy and SLE subjects was determined by flow cytometry using the APC-conjugated 12G5 (empty histograms) or isotype control (filled histogram) mAb. Displayed data are representative plots of the mean fluorescence intensity (MFI) of CXCR4 at the surface of total B cells from a healthy individual and two patients with either inactive or active SLE. (B) The percentage of total $\left(C D 19^{+}\right)$B cells, naive $\left(C D 19^{+} C D 27^{-}\right) B$ cells, memory $\left(C D 19^{+} C D 27^{+}\right) B$ cells and PC (CD19 $\left.{ }^{\text {low }} C D 27^{\text {high }}\right)$ expressing CXCR4 in healthy and SLE subjects are given. Box plots show the median values, $25^{\text {th }}$ and $75^{\text {th }}$ quartile and the range of values. Kruskal-Wallis $H$ test and associated $P$ values are indicated. ${ }^{* * *} P<.0005$ compared with control B cells (as determined using the Mann-Whitney U-test). (C and D) CXCR4-positive fraction (C) or MFI (D) values obtained within total B cells for each SLE patient were plotted as a function of SLEDAI scores. Correlation factor ( $r$, Spearman's) and $P$ value are indicated. 


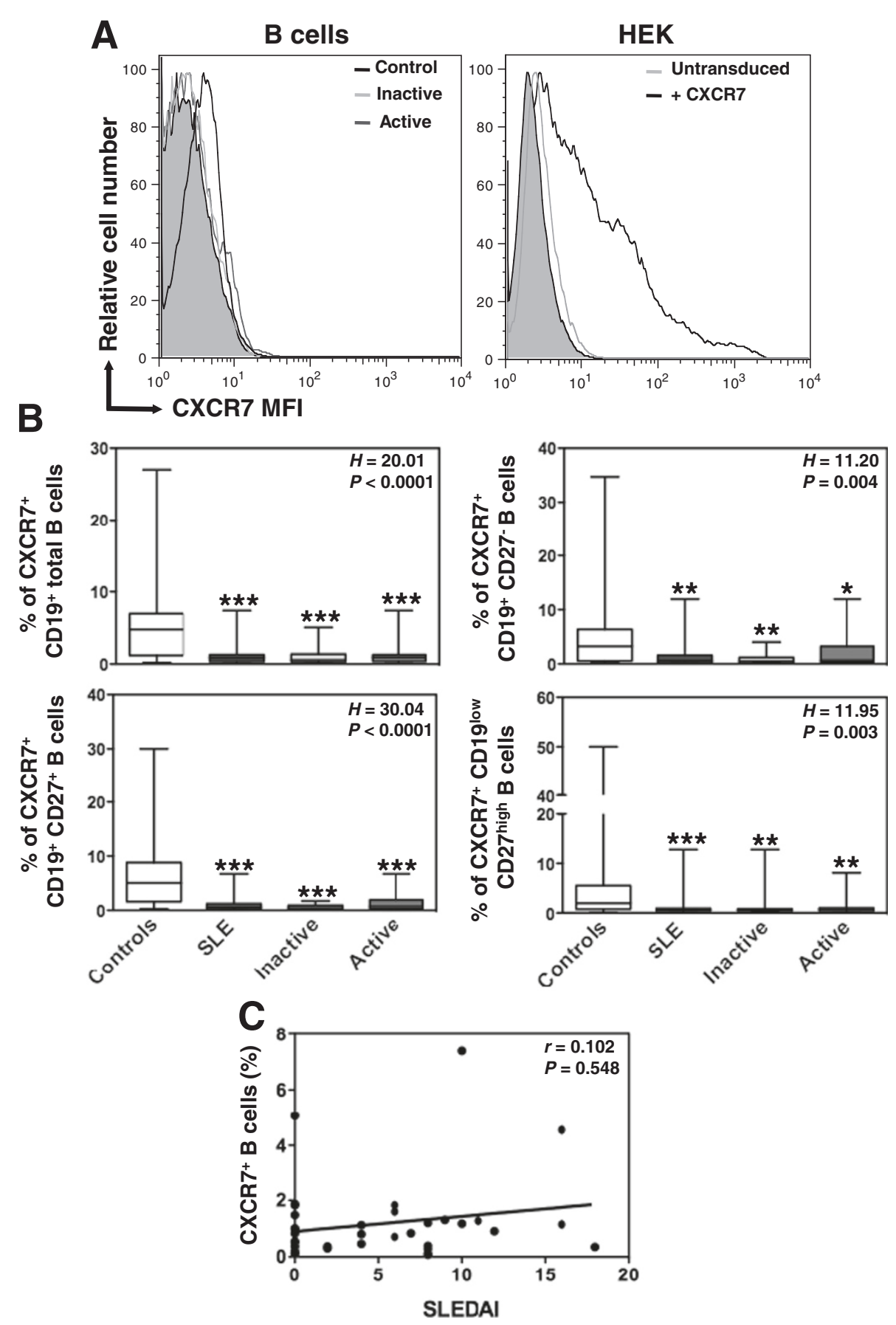

Figure 4 Altered CXCR7 expression on SLE B cells. (A) Surface expression of CXCR7 on CD19 ${ }^{+}$-gated PBMC from healthy and SLE subjects was determined by flow cytometry using the unconjugated $9 \mathrm{C} 4$ (empty histograms) or isotype control (filled histograms) mAb followed by a PEconjugated goat anti-mouse F(ab') 2 Ab. CXCR7-transduced (versus parental) HEK 293 T (HEK) cells were used as a positive control for staining. Displayed data are representative plots of the MFI of CXCR7 at the surface of total B cells from a healthy individual and two patients with either inactive or active SLE (left panel) or of HEK cells transduced with CXCR7 or left untransduced (right panel). (B) The percentage of total (CD19+) B cells, naive (CD19 CD27) B cells, memory $\left(C D 19^{+} \mathrm{CD} 27^{+}\right) \mathrm{B}$ cells and PC (CD19 low $\left.\mathrm{CD} 27^{\text {high }}\right)$ expressing CXCR7 in healthy and SLE subjects are shown. Box plots show the median values, $25^{\text {th }}$ and $75^{\text {th }}$ quartile and the range of values. Kruskal-Wallis $H$ test and associated $P$ values are indicated. ${ }^{*} P<.05,{ }^{*} P<.005$ and ${ }^{* * *} P<.0005$ compared with control B cells (as determined using the Mann-Whitney U-test). (C) CXCR7-positive fraction values obtained within total B cells for each SLE patient were plotted as a function of SLEDAI scores. Correlation factor ( $r$, Spearman's) and $P$ value are indicated. 
membrane CXCR4 and CXCR7 expression was associated with an abnormal intracellular compartmentalization of the receptors.

\section{Intracellular localization of CXCL12 receptors in SLE B lymphocytes}

CXCR4 is mostly expressed at the surface of circulating leukocytes from healthy donors, while its intracellular pool is rather minor $[44,45]$. By contrast, CXCR7 is rarely, or even not, expressed at the membrane of human and mouse leukocytes $[21,29,30,46]$. Some studies indicated that CXCR7 is predominantly localized underneath the plasma membrane [47], while others failed to detect it intracellularly [31]. Stimulated by this puzzling picture of the intracellular detection of CXCR4 and CXCR7, we assessed by flow cytometry the expression of both receptors in $\mathrm{CD} 19^{+}$-gated PBMC after permeabilization. This step allowed detecting relative total, i.e. both cell surface and intracellular, pools of CXCR4 and CXCR7 in B cells. As shown in Figure 5A, the majority of total $\mathrm{B}$ cells from healthy individuals coexpressed CXCR4 and CXCR7 (median value 97\%, range: 51.9 to $99 \%$ ). About $1 \%$ and $3 \%$ of $\mathrm{B}$ cells only expressed CXCR4 or CXCR7, respectively, whereas roughly $<1 \%$ of the cells expressed neither CXCR4 nor CXCR7. A similar pattern was found in the different B-cell subsets (Figure 5B). These findings, combined with those displayed in Figures 3 and 4, confirmed the differential cellular compartmentalization of both CXCR4 and CXCR7, i.e. predominant cell surface detection of CXCR4 (>80\% total pool) and intracellular localization of CXCR7 (>90\% total pool).

The situation was somewhat different in permeabilized PBMC from SLE patients. The fraction of total B cells coexpressing both receptors was slightly decreased by $\sim 20-30 \%$ relative to control cells, while the proportion of B cells expressing only CXCR4 or CXCR7 was significantly increased (Figure 5). The defect in total CXCR4 expression was comparable among naive, memory and PC subsets from patients with either inactive or active disease. These data further revealed a significant intracellular detection of both CXCR4 (>60\% total pool) and CXCR7 ( $>90 \%$ total pool) in SLE B cells. In line with this, geometric MFI values for total pools of CXCR4 and CXCR7 were roughly comparable in B cells from healthy and SLE subjects, while membrane expression levels of CXCR4 were decreased on SLE B cells (Additional file 1: Figure S1). Collectively, our findings established that naive and overall $\mathrm{CD} 27^{+} \mathrm{B}$ cells from both healthy and SLE individuals displayed a nearly exclusive expression of CXCR7 in cytosolic compartments. The loss of membrane CXCR4 expression in SLE B cells was accompanied by its abnormal intracellular localization.
Impaired CXCL12-promoted chemotaxis of SLE B lymphocytes We thus questioned whether impaired compartmentalization of CXCL12 receptors, i.e. decreased at the membrane and increased at the intracellular level, in SLE B cells impacted on CXCL12 responsiveness. We investigated the migratory response of $\mathrm{CD} 19^{+}$-gated $\mathrm{PBMC}$ from healthy and SLE subjects to CXCL12 using a Transwellbased chemotaxis assay. Addition of CXCL12 resulted in a dose-dependent chemotactic response of both control and SLE B cells (Figure 6A). However, SLE B cells displayed weaker migratory responses to all concentrations tested, indicating a lower efficiency of chemotaxis to CXCL12. In contrast, CCR7-dependent migration following CCL19 stimulation was observed to be in the same range for SLE and control B cells. We then compared chemotactic responses of the different B-cell subsets from patients with either inactive or active SLE to those obtained with control cells. The CXCL12 dose was chosen so that migration was detectable for B cells harboring low CXCL12 receptors expression (i.e. SLE group) without reaching saturating concentrations for B cells with higher receptor expression (i.e. control group). Upon exposure to $30 \mathrm{nM}$ CXCL12, the percentage of specific migration of $\mathrm{B}$ cells from healthy donors was of $\sim 15 \%, \sim 30 \%$ and $\sim 40 \%$ in the naive, memory and PC subsets, respectively (Figure 6B). Remarkably, circulating B cells from patients with inactive or active disease shared an impaired CXCL12-promoted chemotaxis, with a significant reduction ( $>60 \%$ as compared to control cells) of specific migration in the three subsets analyzed. Such decrease in migration efficiency was consistent with the severe decrease in CXCR4 expression observed on all SLE B-cell subsets. The residual migration of SLE B cells upon CXCL12 exposure was totally inhibited by the specific CXCR4 antagonist AMD3100 [48]. Overall, these findings suggested that the defect in membrane CXCR4 expression contributes to the loss of CXCL12 responsiveness of SLE B lymphocytes.

\section{Discussion}

In the present study, we provided novel insights to SLE pathophysiology based on the systematic evaluation of CXCL12 receptors expression in circulating B cells from a large cohort of 41 Mexican Mestizos patients. Our findings revealed reduced levels of CXCR4, and to a lesser extent of $C X C R 7$, transcripts in SLE PBMC compared to controls. SLE was associated with a strong defect of membrane CXCR4 expression in naive and Ab-secreting B cells accompanied by an abnormal intracellular detection of CXCR4. CXCR7 was scarcely expressed on control and SLE B cells and predominantly localized in cytosolic compartments. Altered receptor compartmentalization was associated with an impaired CXCL12-promoted migration of SLE B cells. As the majority $(n=23)$ of active patients were treated with at least 

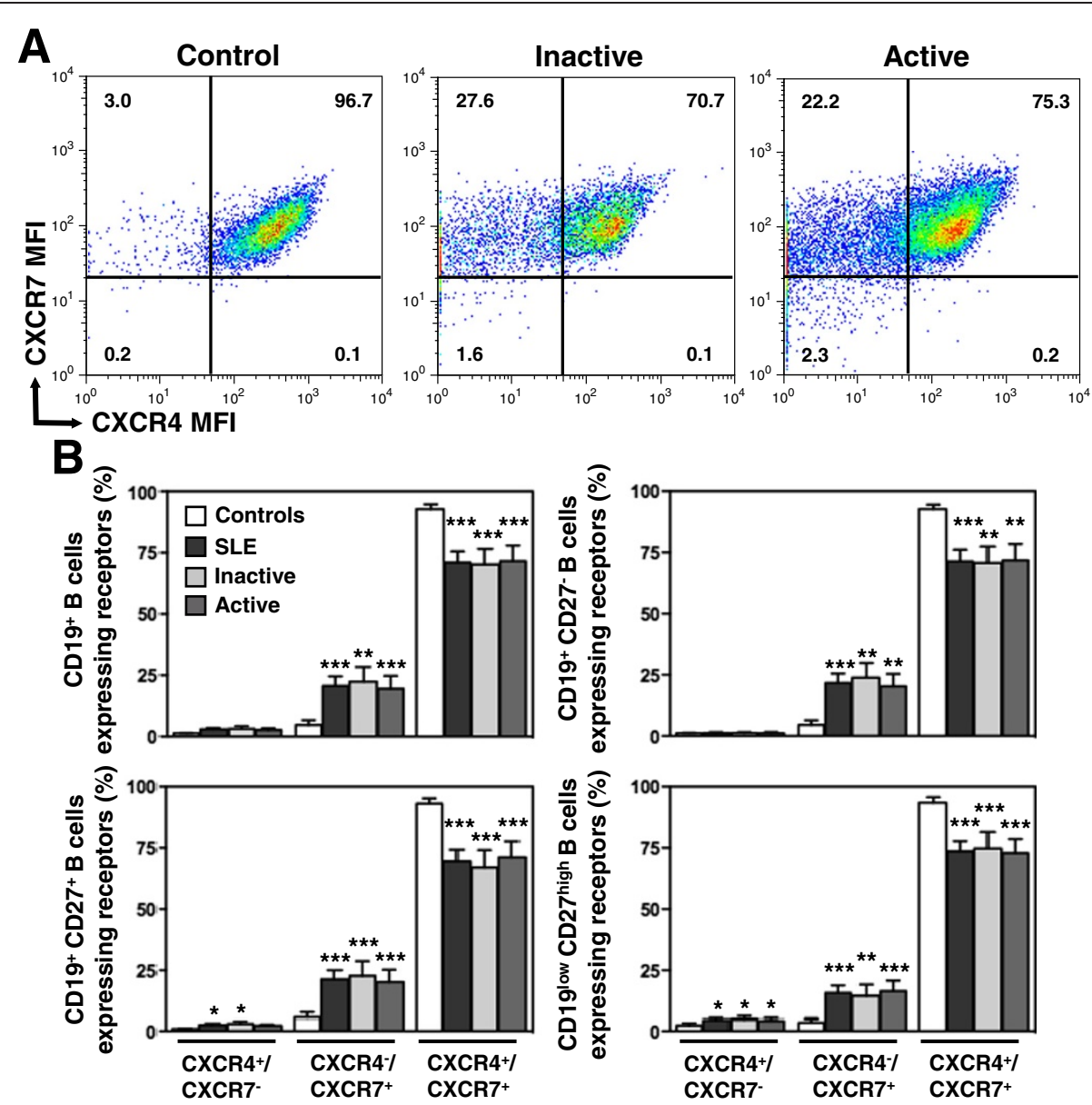

Figure 5 Intracellular localization of CXCR4 and CXCR7 in SLE B cells. (A) Total pools of CXCR4 and CXCR7 were simultaneously detected by flow-cytometric analysis in CD19+-gated PBMC from healthy and SLE subjects. Staining was performed on fixed and permeabilized leukocytes with both 9C4 (PE) and 12G5 (APC) mAbs. Quadrants were set on controls stained with the corresponding isotype control. Representative dotplots demonstrating coexpression of CXCR4 and CXCR7 in total B cells from a healthy individual and two patients with either inactive or active SLE are shown. (B) The proportions (mean \pm SEM) of total $\left(C D 19^{+}\right) B$ cells, naive $\left(C D 19^{+} C D 27\right)$ B cells, memory $\left(C D 19^{+} C D 27^{+}\right) B$ cells and PC $\left(\mathrm{CD} 19^{\text {low }} \mathrm{CD} 27^{\text {high }}\right)$ expressing CXCR4 and/or CXCR7 in healthy and SLE subjects are given. ${ }^{*} P<.05,{ }^{* *} P<.005$ and ${ }^{* * *} P<.0005$ compared with control B cells.

two drugs, we cannot assess the effects of each immunosuppressive therapy on CXCL12 receptors expression and function. Neither disease activity or duration nor muco-cutaneous and renal manifestations significantly influenced CXCR4 and CXCR7 protein expression. Conversely, when we applied a single cut-off at $21.79 \%$ and $0.83 \%$, the respective median value for CXCR4- and CXCR7-positive B cells in the entire cohort, for the classification of patients displaying low or high levels of CXCL12 receptors expression, no clinical difference was found between the two groups $(P=0.52$ and $P=0.21$ for CXCR4 and CXCR7 respectively, Mann-Whitney $U$-test). Thus, it would be worthwhile to investigate groups of active patients with joint/cutaneous, hematological, CNS, and pure renal involvement in order to differentiate how these manifestations impact on receptors expression.
CXCR4 is involved in B-cell differentiation and homing as well as in the inflammatory development and progression of B-cell mediated autoimmune disorders including SLE $[3,13]$. In line with previous works $[13,15,42]$, we observed that the vast majority of circulating total B cells from healthy donors stained for CXCR4, while the frequency of CXCR4-positive B cells decreased upon differentiation. Similarly, an inverse correlation of membrane CXCR4 expression and maturating stage of B cells was detected in SLE patients. However, the frequency of CXCR4-positive B cells within naive, memory and PC subsets was significantly decreased, suggesting that the defect in membrane CXCR4 expression results from an intrinsic CXCR4 anomaly rather than the expansion of a CXCR4-negative B-cell subpopulation. Circulating B cells from patients with either inactive or active disease displayed a comparable defect in 


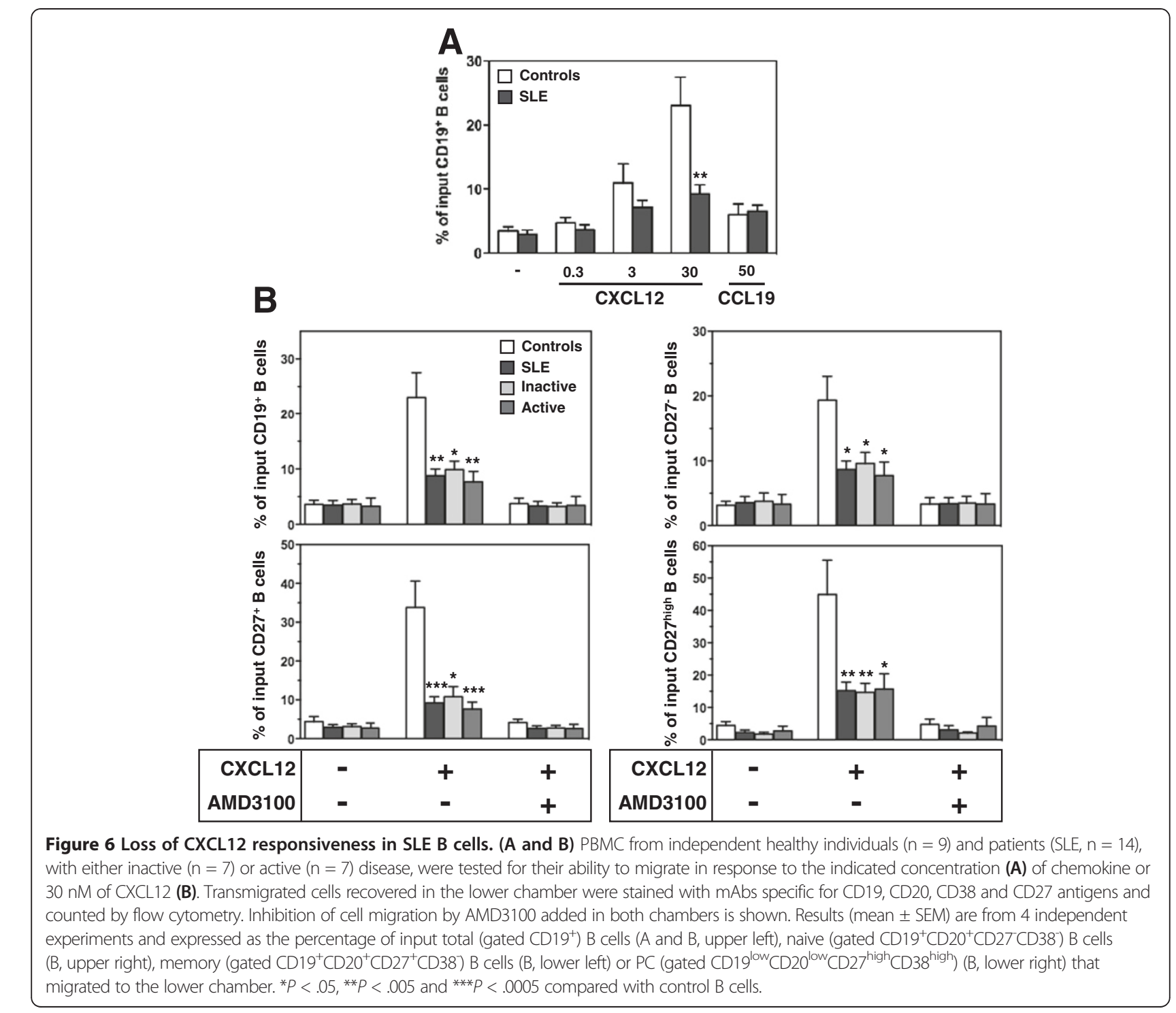

membrane CXCR4 expression, indicating that the disease activity did not impact on the level of CXCR4 expression. Thus, our findings provided evidence that SLE B cells display a loss of membrane CXCR4 expression. In agreement with this, Henneken and coworkers previously showed a decrease in CXCR4-positive naive and overall CD27 ${ }^{+}$B cells from 4 SLE patients [41]. Because CXCR4 is virtually expressed on all B-cell subsets, changes in CXCL12 responsiveness that occur throughout lymphocyte ontogeny were proposed to result from differences in the activation of CXCR4-mediated signaling [15]. For instance, CXCR4 expression is downregulated upon B-cell receptor engagement [49]. It is tempting to speculate that the loss of CXCR4 expression in SLE reflects, at least in part, chronic in vivo B-cell activation.
While there is a relative consensus on CXCR4 anomaly in B cells of several mouse models of lupus nephritis $[13,50]$, the situation is still unclear in humans. Indeed, Wang and coworkers observed increased CXCR4 levels in circulating $B$ and $T$ cells from 31 SLE patients [16]. These findings have been partially confirmed by RodriguezBayona and coworkers who detected in a larger cohort composed of 69 patients a slight increase in CXCR4 expression restricted to non-switched memory B cells and sparing other B-cell subsets [8]. The reasons for discrepancies on CXCR4 profiles between our work and principally that of Wang and coworkers are unclear but may relate to differences in sample handling or ethnical origin of patients [51]. Indeed, whereas Wang and coworkers performed CXCR4 staining on whole blood [16], we analyzed CXCL12 receptors patterns on PBMC, indicating that the Ficoll- 
based isolation could constitute a cause for the differences on CXCR4 expression. However, and in contrast to the recent study by Nieto and coworkers [38], we found only discrete differences in CXCR4 expression at the surface of control B cells after cell isolation as compared to whole blood samples (Additional file 2: Figure S2). Cryopreservation of PBMC might also constitute a source of changes in labile phenotypic markers and B-cell subset distribution. Recently, Faint and coworkers showed that cryopreserved sample batching, and subsequent thawing for deferred analysis, did not alter the proportion of lymphocyte subsets but led to an increased CXCR4 expression on lymphocytes [52]. In our hands, the cryopreservation step indeed influenced positively CXCR4 expression on control B cells (Additional file 2: Figure S2). Thus, this process cannot solely explain the CXCR4 down-regulation we describe here. SLE represents a polygenic disease for which several clinical differences among ethnic groups have been documented [2,53,54]. Having focused on a cohort of 41 Mexican Mestizos patients [34], we differed from other studies, which have assessed CXCR4 expression on lymphocytes from patients with various ethnical origins $[8,16]$. Therefore, we cannot rule out that heterogeneity in the genetic background could account for contradictory results.

The molecular basis underlying the defect in CXCR4 expression on SLE B cells is unclear but might involve both impaired receptor synthesis and intracellular trafficking. We unveiled decreased CXCR4 expression in PBMC from SLE patients. Such transcriptional anomaly, which is consistent with a recent study [18], could result in reduced protein levels in circulating leukocytes including the B-cell compartment. Whether epigenetic (e.g. promoter hypermethylation) or post-transcriptional (e.g. microRNA) regulatory mechanisms account for the decrease in the steady-state levels of CXCR4 mRNAs will be the focus of future investigations on sorted $B$ cells from patients. Our findings were enough indicative to delineate how such transcriptional anomaly could impact on protein levels, especially in circulating B cells. Flow-cytometric analysis revealed a significant decrease in the total pool of CXCR4 together with an impaired compartmentalization of the receptor, i.e. reduced at the cell surface and increased at the intracellular level, in all B-cell subsets from SLE patients irrespective of their disease activity status. The different cytokine milieu in SLE patients could alter the expression and activity of CXCR4. An increase in serum TNF- $\alpha$ and type I IFN levels is characteristic of SLE [11] and both cytokines are known to down-regulate CXCR4 [55,56]. The proinflammatory cytokine IL-17 might be involved in such phenomenon, as it increased in the serum of SLE patients [57] and down-modulated the responsiveness of germinal center B cells to Cxcl12 in autoimmune BXD2 mice [58]. Interestingly, an increase of CXCL12 in the serum of SLE patients has been reported [59]. Since CXCR4 engagement upon CXCL12 stimulation paradigmatically leads to receptor internalization, one can speculate that chronic exposure to CXCL12 is another potential explanation for abnormal CXCR4 expression on autoreactive B cells.

The study was extended to the expression of CXCR7, which is another receptor for CXCL12 but, unlike CXCR4, it has never been investigated in the context of lupus pathogenesis. Surface expression of CXCR7 is well documented on activated endothelium, fetal liver cells, neurons and multiple cancer cells $[19,60]$. Many groups have detected CXCR7 products in mouse and human leukocytes, although one study challenged this view $[31,33]$. Our real-time PCR-based analysis permitted to readily detect mRNAs encoding CXCR7 in PBMC from healthy subjects, further corroborating previous studies demonstrating unambiguously transcript amplification in mouse and human monocytes, dendritic cells, $\mathrm{CD} 4^{+}$ T cells, neutrophils and B cells $[19,30,33,61,62]$. Nevertheless, SLE leukocytes displayed a slight decrease in the steady-state level of $C X C R 7$ transcripts. Further in-depth studies are required to determine whether transcriptional regulatory mechanisms account for heterogeneous CXCR7 expression in SLE. Like for CXCR4, we found no differences in CXCR7 expression at the surface of control B cells after Ficoll-based cell isolation as compared to whole blood samples (Additional file 3: Figure S3). In contrast, the cryopreservation step led to a reduced CXCR7 expression on B cells. Thus, we cannot exclude that cryopreserved sample batching contributes to low levels of CXCR7 on SLE B cells.

Intracellular compartmentalization of CXCL12 receptors was simultaneously assessed by flow cytometry after cell permeabilization, and in line with previous works [20,47], unraveled that CXCR7 predominantly localized in cytosolic compartments of B-cell subsets from healthy and SLE subjects. Such peculiar intracellular pattern is consistent with the notion that CXCR7 rapidly cycles between the plasma membrane and intracellular compartments either spontaneously or upon exposure to its ligand $[20,24,28,47]$. The main function of endotheliumexpressed CXCR7 is likely sequestration of CXCL12 as proposed in homeostatic and pathological, including autoimmune, conditions $[24,46]$. Additionally, mouse CXCR7 seems to function as a sink for CXCL12 and contributes to marginal zone B-cell retention as well as kidney development $[22,63]$. Recently, we identified CXCR7 as an active scavenger for CXCL12 on human tonsil-derived B cells [33]. Although the relevance of this activity in human B-cell homeostasis remains to be determined, one can speculate that CXCR7 acts as a decoy receptor in B cells, thereby clearing CXCL12 from the surrounding medium 
and controlling CXCR4 expression and/or signaling. A crosstalk between intracellular CXCR4 and CXCR7 could also be involved in the modulation of CXCL12 activities as previously proposed [47]. Finally, we cannot exclude that defective CXCR4 and CXCR7 expression in SLE leukocytes impacts on the anterograde trafficking, i.e. from synthesis in the endoplasmic reticulum to the plasma membrane, of both receptors, resulting in their altered cellular distribution [64]. Studying the relevance of CXCR7 in B-cell biology was not in the scope of this study but clearly deserves further investigations using selective antagonists for CXCR4 and CXCR7.

\section{Conclusions}

Our findings highlight a previously unappreciated downregulation of CXCR4 and CXCR7 on circulating B cells from SLE patients. Such anomaly is associated with intracellular localization of both receptors and a loss of CXCL12 responsiveness. This is the first study assessing simultaneously the status of CXCL12 receptors in autoimmune-biased B cells. This work offers important pathophysiological insights into the migratory behavior of autoreactive B cells from SLE patients, potentially permitting new therapeutic avenues.

\section{Additional files}

Additional file 1: Figure S1. Distribution of CXCR4 and CXCR7 in SLE B cells. (A) Expression of CXCR4 on CD19 ${ }^{+}$-gated PBMC from SLE patients $(n=41)$, distributed according to disease activity, i.e. inactive $(n=17)$ versus active $(n=24)$, and healthy individuals $(n=45)$ was determined by flowcytometric analysis (FACSCalibur, BD Biosciences) using the APC-conjugated 12G5 mAb. The geometric mean fluorescence intensity (MFI) of CXCR4 at the surface of total $\left(C D 19^{+}\right) B$ cells, naive $\left(C D 19^{+} C D 27\right) B$ cells, memory $\left(C D 19^{+} C D 27^{+}\right) B$ cells and PC (CD19 $\left.{ }^{\text {low }} C D 27^{\text {high }}\right)$ from healthy and SLE subjects are displayed. (B) Total pools of CXCR4 and CXCR7 were detected by flow cytometry by staining fixed and permeabilized leukocytes with $9 C 4$ (PE) and 12G5 (APC) mAbs. The geometric MFI of CXCR4 or CXCR7 was evaluated in total $B$ cells. Box plots show the median values, $25^{\text {th }}$ and $75^{\text {th }}$ quartile and the range of values. Kruskal-Wallis $H$ test and associated $P$ values are indicated. ${ }^{* * *} P<.0005$ compared with control B cells. ${ }^{5} P<.05$ compared with B cells from patients with inactive SLE (as determined using the Mann-Whitney U-test).

Additional file 2: Figure S2. Sample processing modulates membrane CXCR4 expression. (A) Membrane expression of CXCR4 on control CD19+-gated B cells was determined by flow-cytometric (FACS Fortessa, BD Biosciences) analysis using the PE-conjugated 12G5 (empty histograms) or isotype control (filled histogram) mAb. Displayed data are representative plots of the MFI of CXCR4 at the surface of total B cells from 4 independent healthy Caucasian women (age median 35 years, range: 24 to 47 years) obtained either after staining on whole blood (Blood) or fresh (Ficoll) or cryopreserved (Cryo) PBMC. (B) The percentage of total $\left(C D 19^{+}\right)$B cells, naive $\left(C D 19^{+} \mathrm{CD} 27\right) \mathrm{B}$ cells, memory $\left(\mathrm{CD} 19^{+} \mathrm{CD} 27^{+}\right) \mathrm{B}$ cells and plasma cells (CD19 ${ }^{\text {low }}$ CD2 $7^{\text {high }}$ ) expressing CXCR4 are given. Box plots show the median values, 25th and 75th quartile and the range of values. (C) The geometric MFI of CXCR4 was evaluated for all aforementioned B-cell subsets. ${ }^{*} P<.05$, ${ }^{* * P}<.005$ and ${ }^{* * *} P<.0005$ compared with whole blood-gated B cells.

Additional file 3: Figure S3. Sample processing modulates membrane CXCR7 expression. (A) Surface expression of CXCR7 on CD19 ${ }^{+}$-gated B cells from 4 independent healthy Caucasian women was determined by flow cytometry using the unconjugated 9C4 (empty histograms) or isotype control (filled histograms) mAb followed by a PE-conjugated goat anti-mouse $F\left(a b^{\prime}\right)_{2} A b$. Displayed data are representative plots of the MFI of CXCR7 at the surface of total B cells obtained either after staining on whole blood (Blood) or fresh (Ficoll) or cryopreserved (Cryo) PBMC. (B) The percentage of total $\left(\mathrm{CD} 19^{+}\right) \mathrm{B}$ cells, naive $\left(\mathrm{CD} 19^{+} \mathrm{CD} 27^{-}\right) \mathrm{B}$ cells, memory $\left(\mathrm{CD} 19^{+} \mathrm{CD} 27^{+}\right) \mathrm{B}$ cells and plasma cells (CD19 ${ }^{\text {low }} \mathrm{CD} 27^{\text {high }}$ ) expressing CXCR7 are given. Box plots show the median values, 25th and 75th quartile and the range of values. (C) The geometric MFI of CXCR7 was evaluated for all B-cell subsets. ${ }^{*} P<.05$ and ${ }^{*} P<.005$ compared with whole blood-gated B cells.

\section{Abbreviations}

Ab: Antibody; APC: Allophycocyanin; BSA: Bovine serum albumin; CNS: Central nervous system; FCS: Fetal calf serum; FITC: Fluorescein isothiocyanate; MFI: Mean fluorescence intensity; NP: Neuropsychiatric; PBMC: Peripheral blood mononuclear cells; PC: Plasma cells; PE: Phycoerythrin; PerCp-Cy5: Peridinin chlorophyll protein-Cy5; SDF1: Stromal cell Derived Factor-1; SLE: Systemic Lupus Erythematosus; SLEDAl: Systemic Lupus Erythematosus Disease Activity Index.

\section{Competing interests}

The authors declare that they have no competing interests.

\section{Authors' contributions}

Conceived and designed the experiments: $\mathrm{VB}, \mathrm{AB}, \mathrm{DE}$ and $\mathrm{KB}$. Performed the experiments: $V B, A B, C F$ and $K B$. Analyzed the data: $V B, A B, C F$ and $K B$. Wrote the paper: $V B, A B$ and $K B$. Provided funding: $D E$ and $K B$. Provided experimental tools and contributed to manuscript editing: VM, MT and LL. Provided patient samples and clinical features: GL, JJ-O and LL. All authors read and approved the final manuscript.

\section{Acknowledgements}

We thank V. Godié (Université Paris-Sud, Laboratoire "Cytokines, Chimiokines et Immunopathologie", INSERM UMR_S996, Clamart, France) for excellent technical assistance, $\mathrm{H}$. Tharinger (Plateforme d'Immunomonitorage, Institut Paris-Sud d'Innovation Thérapeutique, Clamart) for editing the manuscript, and Dr. F. Baleux (Unité de Chimie Organique, Institut Pasteur, Paris, France) for providing us with CXCL12. We are grateful to Drs. V. Machelon and F. Bachelerie (INSERM UMR_S996) for critical reading of the manuscript. This work was supported by the Assistance Publique-Hôpitaux de Paris (AP-HP, grant number 07018) and the Agence Nationale de la Recherche (ANR, grant number $2010 \mathrm{JCJC} 1104$ 01). V.B., A.B., C.F., V.M., D.E. and K.B. are members of the Laboratory of Excellence LERMIT supported by a grant from ANR (Investissements d'Avenir). V.B., A.B. and C.F. are fellowship recipients from the Fondation pour la Recherche Médicale, the French Ministry and the DIM Biothérapies, respectively. M.T. was supported by funds obtained from the Gottfried und Julia Bangerter-Rhyner-Stiftung, Basel, the Helmut Horten Foundation and the Fondazione Ticinese per la Rcicerca sul Cancro.

\section{Author details}

'Université Paris-Sud, Laboratoire "Cytokines, Chimiokines et Immunopathologie", UMR_S996, Clamart, France. ${ }^{2}$ INSERM, Laboratory of Excellence in Research on Medication and Innovative Therapeutics (LERMIT), Clamart, France. ${ }^{3}$ Service de Médecine Interne et d'Immunologie Clinique, AP-HP, Hôpital Antoine-Béclère, Clamart, France. ${ }^{4}$ Institute for Research in Biomedicine, Bellinzona, Switzerland. ${ }^{5}$ Department of Immunology and Rheumatology, Instituto Nacional de Ciencias Mèdicas y Nutriciòn Salvador Zubiràn, Mexico City, Mexico. ${ }^{6}$ Service de Microbiologie-Immunologie Biologique, AP-HP, Hôpital Antoine-Béclère, Clamart, France.

Received: 18 September 2012 Accepted: 14 December 2012 Published: 18 December 2012

\section{References}

1. Rahman A, Isenberg DA: Systemic lupus erythematosus. N Engl J Med 2008, 358:929-939.

2. Deng Y, Tsao BP: Genetic susceptibility to systemic lupus erythematosus in the genomic era. Nat Rev Rheumatol 2010, 6:683-692.

3. Mitchison NA, Wedderburn LR: B cells in autoimmunity. Proc Natl Acad Sci USA 2000, 97:8750-8751. 
4. Nashi $E$, Wang $Y$, Diamond B: The role of $B$ cells in lupus pathogenesis. Int J Biochem Cell Biol 2010, 42:543-550.

5. Deshmukh US, Bagavant H, Fu SM: Role of anti-DNA antibodies in the pathogenesis of lupus nephritis. Autoimmun Rev 2006, 5:414-418.

6. Jacobi AM, Odendahl M, Reiter K, Bruns A, Burmester GR, Radbruch A, Valet G, Lipsky PE, Dorner T: Correlation between circulating CD27high plasma cells and disease activity in patients with systemic lupus erythematosus. Arthritis Rheum 2003, 48:1332-1342.

7. Pisetsky DS, Grammer AC, Ning TC, Lipsky PE: Are autoantibodies the targets of B-cell-directed therapy? Nat Rev Rheumatol 2011, 7:551-556.

8. Rodriguez-Bayona B, Ramos-Amaya A, Perez-Venegas JJ, Rodriguez C, Brieva JA: Decreased frequency and activated phenotype of blood CD27 IgD IgM B lymphocytes is a permanent abnormality in systemic lupus erythematosus patients. Arthritis Res Ther 2010, 12:R108.

9. Daridon C, Blassfeld D, Reiter K, Mei HE, Giesecke C, Goldenberg DM Hansen A, Hostmann A, Frolich D, Dorner T: Epratuzumab targeting of CD22 affects adhesion molecule expression and migration of B-cells in systemic lupus erythematosus. Arthritis Res Ther 2010, 12:R204.

10. Thelen M, Stein JV: How chemokines invite leukocytes to dance. Nat Immunol 2008, 9:953-959.

11. Ohl K, Tenbrock K: Inflammatory cytokines in systemic lupus erythematosus. J Biomed Biotechnol 2011, 2011:432595.

12. Ezzat M, El-Gammasy T, Shaheen $\mathrm{K}$, Shokr E: Elevated production of serum B-cell-attracting chemokine-1 (BCA-1/CXCL13) is correlated with childhood-onset lupus disease activity, severity, and renal involvement. Lupus 2011, 20:845-854.

13. Chong BF, Mohan C: Targeting the CXCR4/CXCL12 axis in systemic lupus erythematosus. Expert Opin Ther Targets 2009, 13:1147-1153.

14. Ansel KM, Cyster JG: Chemokines in lymphopoiesis and lymphoid organ development. Curr Opin Immunol 2001, 13:172-179.

15. Palmesino E, Moepps B, Gierschik P, Thelen M: Differences in CXCR4mediated signaling in B cells. Immunobiology 2006, 211:377-389.

16. Wang A, Guilpain P, Chong BF, Chouzenoux S, Guillevin L, Du Y, Zhou XJ, Lin F, Fairhurst AM, Boudreaux C, et al: Dysregulated expression of CXCR4/ CXCL12 in subsets of patients with systemic lupus erythematosus. Arthritis Rheum 2010, 62:3436-3446.

17. Balabanian K, Couderc J, Bouchet-Delbos L, Amara A, Berrebi D, Foussat A, Baleux F, Portier A, Durand-Gasselin I, Coffman RL, et al: Role of the chemokine stromal cell-derived factor 1 in autoantibody production and nephritis in murine lupus. J Immunol 2003, 170:3392-3400.

18. Lugar PL, Love C, Grammer AC, Dave SS, Lipsky PE: Molecular characterization of circulating plasma cells in patients with active systemic lupus erythematosus. PLoS One 2012, 7:e44362.

19. Thelen M, Thelen S: CXCR7, CXCR4 and CXCL12: an eccentric trio? J Neuroimmunol 2008, 198:9-13.

20. Ulvmar MH, Hub E, Rot A: Atypical chemokine receptors. Exp Cell Res 2011, 317:556-568.

21. Naumann U, Cameroni E, Pruenster M, Mahabaleshwar H, Raz E, Zerwes HG, Rot A, Thelen M: CXCR7 functions as a scavenger for CXCL12 and CXCL11. PLoS One 2010, 5:e9175.

22. Wang H, Beaty N, Chen S, Qi CF, Masiuk M, Shin DM, Morse HC 3rd: The CXCR7 chemokine receptor promotes B-cell retention in the splenic marginal zone and serves as a sink for CXCL12. Blood 2011, 119:465-468

23. Luker KE, Steele JM, Mihalko LA, Ray P, Luker GD: Constitutive and chemokine-dependent internalization and recycling of CXCR7 in breast cancer cells to degrade chemokine ligands. Oncogene 2010, 29:4599-4610.

24. Hoffmann F, Muller W, Schutz D, Schulz S, Stumm R: The CXCR7 C-terminal domain mediates efficient CXCL12 uptake and degradation. J Biol Chem 2012, 287:28362-28377.

25. Rajagopal S, Kim J, Ahn S, Craig S, Lam CM, Gerard NP, Gerard C, Lefkowitz RJ: Beta-arrestin- but not G protein-mediated signaling by the "decoy" receptor CXCR7. Proc Natl Acad Sci USA 2010, 107:628-632.

26. Levoye A, Balabanian K, Baleux F, Bachelerie F, Lagane B: CXCR7 heterodimerizes with CXCR4 and regulates CXCL12-mediated $\mathrm{G}$ protein signaling. Blood 2009, 113:6085-6093.

27. Decaillot FM, Kazmi MA, Lin Y, Ray-Saha S, Sakmar TP, Sachdev P: CXCR7/ CXCR4 Heterodimer Constitutively Recruits \{beta\}-Arrestin to Enhance Cell Migration. J Biol Chem 2011, 286:32188-32197.

28. Canals M, Scholten DJ, de Munnik S, Han MK, Smit MJ, Leurs R: Ubiquitination of CXCR7 controls receptor trafficking. PLoS One 2012, 7:e34192.
29. Balabanian K, Lagane B, Infantino S, Chow KY, Harriague J, Moepps B, Arenzana-Seisdedos F, Thelen M, Bachelerie F: The chemokine SDF-1/ CXCL12 binds to and signals through the orphan receptor RDC1 in T lymphocytes. J Biol Chem 2005, 280:35760-35766.

30. Infantino S, Moepps B, Thelen M: Expression and regulation of the orphan receptor RDC1 and its putative ligand in human dendritic and B cells. $\mathrm{J}$ Immunol 2006, 176:2197-2207.

31. Berahovich RD, Zabel BA, Penfold ME, Lewen S, Wang Y, Miao Z, Gan L, Pereda J, Dias J, Slukvin II, et al: CXCR7 protein is not expressed on human or mouse leukocytes. J Immunol 2010, 185:5130-5139.

32. Jacobi AM, Reiter K, Mackay M, Aranow C, Hiepe F, Radbruch A, Hansen A, Burmester GR, Diamond B, Lipsky PE, Dorner T: Activated memory B cell subsets correlate with disease activity in systemic lupus erythematosus: delineation by expression of CD27, IgD, and CD95. Arthritis Rheum 2008, 58:1762-1773.

33. Humpert ML, Tzouros M, Thelen S, Bignon A, Levoye A, Arenzana-Seisdedos F, Balabanian K, Bachelerie F, Langen H, Thelen M: Complementary methods provide evidence for the expression of CXCR7 on human $B$ cells. Proteomics 2012, 12:1938-1948.

34. Juarez-Cedillo T, Zuniga J, Acuna-Alonzo V, Perez-Hernandez N, RodriguezPerez JM, Barquera R, Gallardo GJ, Sanchez-Arenas R, Garcia-Pena Mdel C, Granados J, Vargas-Alarcon G: Genetic admixture and diversity estimations in the Mexican Mestizo population from Mexico City using 15 STR polymorphic markers. Forensic Sci Int Genet 2008, 2:e37-e39.

35. Tan EM, Cohen AS, Fries JF, Masi AT, McShane DJ, Rothfield NF, Schaller JG, Talal N, Winchester RJ: The 1982 revised criteria for the classification of systemic lupus erythematosus. Arthritis Rheum 1982, 25:1271-1277.

36. Bombardier C, Gladman DD, Urowitz MB, Caron D, Chang CH: Derivation of the SLEDAI. a disease activity index for lupus patients. the committee on prognosis studies in SLE. Arthritis Rheum 1992, 35:630-640.

37. Yee CS, Farewell VT, Isenberg DA, Griffiths B, Teh LS, Bruce IN, Ahmad Y, Rahman A, Prabu A, Akil M, et al: The use of systemic lupus erythematosus disease activity index-2000 to define active disease and minimal clinically meaningful change based on data from a large cohort of systemic lupus erythematosus patients. Rheumatology (Oxford) 2011, 50:982-988.

38. Nieto JC, Canto E, Zamora C, Ortiz MA, Juarez C, Vidal S: Selective loss of chemokine receptor expression on leukocytes after cell isolation. PLOS One 2012, 7:e31297.

39. Balabanian K, Levoye A, Klemm L, Lagane B, Hermine O, Harriague J, Baleux F, Arenzana-Seisdedos F, Bachelerie F: Leukocyte analysis from WHIM syndrome patients reveals a pivotal role for GRK3 in CXCR4 signaling. J Clin Invest 2008, 118:1074-1084.

40. Cikos S, Bukovska A, Koppel J: Relative quantification of mRNA: comparison of methods currently used for real-time PCR data analysis. BMC Mol Biol 2007, 8:113.

41. Henneken M, Dorner T, Burmester GR, Berek C: Differential expression of chemokine receptors on peripheral blood $B$ cells from patients with rheumatoid arthritis and systemic lupus erythematosus. Arthritis Res Ther 2005, 7:R1001-R1013.

42. Payne D, Drinkwater $S$, Baretto R, Duddridge $M$, Browning MJ: Expression of chemokine receptors CXCR4, CXCR5 and CCR7 on B and T lymphocytes from patients with primary antibody deficiency. Clin Exp Immunol 2009, 156:254-262.

43. Jin Z, Nagakubo D, Shirakawa AK, Nakayama T, Shigeta A, Hieshima K, Yamada Y, Yoshie O: CXCR7 is inducible by HTLV-1 Tax and promotes growth and survival of HTLV-1-infected T cells. Int J Cancer 2009, 125:2229-2235.

44. Kumar A, Kremer KN, Dominguez D, Tadi M, Hedin KE: Galpha13 and Rho mediate endosomal trafficking of CXCR4 into Rab11+ vesicles upon stromal cell-derived factor-1 stimulation. J Immunol 2011, 186:951-958.

45. Balabanian K, Lagane B, Pablos JL, Laurent L, Planchenault T, Verola O, Lebbe C, Kerob D, Dupuy A, Hermine O, et al: WHIM syndromes with different genetic anomalies are accounted for by impaired CXCR4 desensitization to CXCL12. Blood 2005, 105:2449-2457.

46. Cruz-Orengo L, Holman DW, Dorsey D, Zhou L, Zhang P, Wright M, McCandless EE, Patel JR, Luker GD, Littman DR, et al: CXCR7 influences leukocyte entry into the CNS parenchyma by controlling abluminal CXCL12 abundance during autoimmunity. J Exp Med 2011, 208:327-339.

47. Hartmann TN, Grabovsky V, Pasvolsky R, Shulman Z, Buss EC, Spiegel A, Nagler A, Lapidot T, Thelen M, Alon R: A crosstalk between intracellular CXCR7 and CXCR4 involved in rapid CXCL12-triggered integrin activation 
but not in chemokine-triggered motility of human T lymphocytes and CD34+ cells. J Leukoc Biol 2008, 84:1130-1140.

48. Rettig MP, Ramirez P, Nervi B, DiPersio JF: CXCR4 and mobilization of hematopoietic precursors. Methods Enzymol 2009, 460:57-90.

49. Bleul CC, Schultze JL, Springer TA: B lymphocyte chemotaxis regulated in association with microanatomic localization, differentiation state, and $B$ cell receptor engagement. J Exp Med 1998, 187:753-762.

50. Wang A, Fairhurst AM, Tus K, Subramanian S, Liu Y, Lin F, Igarashi P, Zhou XJ, Batteux F, Wong D, et al: CXCR4/CXCL12 hyperexpression plays a pivotal role in the pathogenesis of lupus. J Immunol 2009, 182:4448-4458.

51. Maecker HT, McCoy JP Jr, Amos M, Elliott J, Gaigalas A, Wang L, Aranda R, Banchereau J, Boshoff C, Braun J, et al: A model for harmonizing flow cytometry in clinical trials. Nat Immunol 2010, 11:975-978.

52. Faint JM, Tuncer C, Garg A, Adams DH, Lalor PF: Functional consequences of human lymphocyte cryopreservation: implications for subsequent interactions of cells with endothelium. J Immunother 2011, 34:588-596.

53. Costenbader KH, Desai A, Alarcon GS, Hiraki LT, Shaykevich T, Brookhart MA Massarotti E, Lu B, Solomon DH, Winkelmayer WC: Trends in the incidence, demographics, and outcomes of end-stage renal disease due to lupus nephritis in the US from 1995 to 2006. Arthritis Rheum 2011, 63:1681-1688.

54. Uribe AG, Romero-Diaz J, Apte M, Fernandez M, Burgos PI, Reveille JD, Sanchez-Guerrero J, Alarcon GS: Impact of immigration on the clinical expression of systemic lupus erythematosus: a comparative study of Hispanic patients residing in the USA and Mexico. Rheumatology (Oxford) 2009, 48:1392-1397.

55. Annunziato F, Cosmi L, Galli G, Beltrame C, Romagnani P, Manetti R, Romagnani S, Maggi E: Assessment of chemokine receptor expression by human Th1 and Th2 cells in vitro and in vivo. J Leukoc Biol 1999, 65:691-699.

56. Postal M, Appenzeller S: The role of tumor necrosis factor-alpha (TNFalpha) in the pathogenesis of systemic lupus erythematosus. Cytokine 2011, 56:537-543.

57. Doreau A, Belot A, Bastid J, Riche B, Trescol-Biemont MC, Ranchin B, Fabien $N$, Cochat P, Pouteil-Noble C, Trolliet P, et al: Interleukin 17 acts in synergy with $B$ cell-activating factor to influence $B$ cell biology and the pathophysiology of systemic lupus erythematosus. Nat Immunol 2009, 10:778-785.

58. Hsu HC, Yang P, Wang J, Wu Q, Myers R, Chen J, Yi J, Guentert T, Tousson A, Stanus AL, et al: Interleukin 17-producing T helper cells and interleukin 17 orchestrate autoreactive germinal center development in autoimmune BXD2 mice. Nat Immunol 2008, 9:166-175.

59. Robak E, Kulczycka L, Sysa-Jedrzejowska A, Wierzbowska A, Robak T: Circulating proangiogenic molecules PIGF, SDF-1 and sVCAM-1 in patients with systemic lupus erythematosus. Eur Cytokine Netw 2007, 18:181-187.

60. Sanchez-Alcaniz JA, Haege S, Mueller W, Pla R, Mackay F, Schulz S, LopezBendito G, Stumm R, Marin O: Cxcr7 controls neuronal migration by regulating chemokine responsiveness. Neuron 2011, 69:77-90.

61. Winkelmann R, Sandrock L, Porstner M, Roth E, Mathews M, Hobeika E, Reth M, Kahn ML, Schuh W, Jack HM: B cell homeostasis and plasma cell homing controlled by Kruppel-like factor 2. Proc Natl Acad Sci USA 2011, 108:710-715.

62. Sierro F, Biben C, Martinez-Munoz L, Mellado M, Ransohoff RM, Li M, Woehl B, Leung H, Groom J, Batten M, et al: Disrupted cardiac development but normal hematopoiesis in mice deficient in the second CXCL12/SDF-1 receptor, CXCR7. Proc Natl Acad Sci USA 2007, 104:14759-14764.

63. Haege S, Einer C, Thiele S, Mueller W, Nietzsche S, Lupp A, Mackay F, Schulz S, Stumm R: CXC Chemokine receptor 7 (CXCR7) regulates CXCR4 protein expression and capillary tuft development in mouse kidney. PLoS One 2012, 7:e42814.

64. Odemis V, Boosmann $K$, Heinen A, Kury P, Engele J: CXCR7 is an active component of SDF-1 signalling in astrocytes and Schwann cells. J Cell Sci 2010, 123:1081-1088.

doi:10.1186/1479-5876-10-251

Cite this article as: Biajoux et al:: Expression of CXCL12 receptors in B cells from Mexican Mestizos patients with systemic lupus erythematosus. Journal of Translational Medicine 2012 10:251.

\section{Submit your next manuscript to BioMed Central and take full advantage of:}

- Convenient online submission

- Thorough peer review

- No space constraints or color figure charges

- Immediate publication on acceptance

- Inclusion in PubMed, CAS, Scopus and Google Scholar

- Research which is freely available for redistribution

Submit your manuscript at www.biomedcentral.com/submit
() Biomed Central 